\title{
Multi-Criterion Approach for Condition Evaluation of Hydro Generator Stator Core
}

\author{
${ }^{1}$ O.P. Rahi, ${ }^{2}$ A.K. Chandel and ${ }^{3}$ M.G. Sharma \\ ${ }^{1,2}$ Department of Electrical Engineering, NIT Hamirpur (HP), India \\ ${ }^{3} \mathrm{HP}$ State Electricity Board, Hamirpur (HP), India
}

\begin{abstract}
Hydropower is considered best option among all the power generation techniques from the view point of its renewable nature, low running cost and environment friendly nature. The four major components of the generators identified are stator winding, stator core, rotor, mechanical components and external factors. In this study, the stator core which is a main component of a generator has been considered for condition evaluation/monitoring. This study presents a new and noble empirical technique for the evaluation of the condition of the hydro generators. The main aspects of hydro generator stator have been taken into consideration for condition evaluation of stator core. A new approach known as multi-criterion analysis for assessing the condition of generator has been proposed and accordingly decision can be taken by utility managers for its rehabilitation. The various factors influencing the performance of stator core of a generator have been further classified in their sub-components and have been given scores and depending upon the score of individual sub-components owing to their condition, possible conditions have been calculated. These calculated factors implies that which type of rehabilitation approach needs to be implemented for optimal performance of the machine also, it results in extended life of the equipment.
\end{abstract}

Key words: Attribute, design, eddy current, lamination, rehabilitation, stacking, visual inspection

\section{INTRODUCTION}

Hydroelectricity is generated from water by converting potential energy of water at a suitable height by rotating a hydraulic turbine which runs in turn the generator coupled to it. The whole principle of electricity generation is based upon the Faraday's law of electromagnetism. The quantum of this generated electricity depends upon two factors, i.e., volume of water and the head. The hydro generator is one of the major equipment to convert the mechanical energy of turbine into electrical energy. The main components of the hydro generator are stator core, stator winding, rotor, mechanical components. These generators also like other equipment are subjected to various different operating conditions which causes deterioration, tearing and wearing and thus resulting in premature aging, de-rating and inefficient operation of hydro power plants. The causes of this unwanted operation of a power plant may attribute to the problems arising in various parts of the generators like stator core, stator winding, rotor, mechanical components and even external factors like type of the plant, nature of the power system and loads thereon and turbine condition.

The main function of the stator core in a generator is to house the stationary stator winding and provide magnetic path for establishing electromagnetic flux. The core is made up of thin lamination of silicon steel or CRGO sheets and these laminations are insulated from each other.

The core is laminated to reduce eddy current losses and to minimize hysteresis loss silicon is added to core material. These stator cores are stacked in the group of 10-24 which are very large in number for a generator. The magnetic flux densities are handled by stator core in the stator teeth and yoke area. This changing alternating flux produces voltage and current which in turn are sources of core losses. Besides losses, the alternating effect leads to vibrations, this is considered one of the major reasons for failure of the core. The slow decaying of inter laminar insulation can also bring down the performance of the core. The potential reasons for the core failure depending upon the design imperfections and operational conditions are as given:

- Application of inadequate pressure during piling of core plates

- Use of resilient material excessively which will relax later leading to imperfection in design

- The thermal aging of the stator core owing to over heating

- Breakdown of inter laminar insulation due to excessive eddy current flow. This may also cause overheating of the core

Corresponding Author: A.K. Chandel, Department of Electrical Engineering, NIT Hamirpur (HP), India 
Int. J. Elec. Power Eng., 5 (4): 161-165, 2011

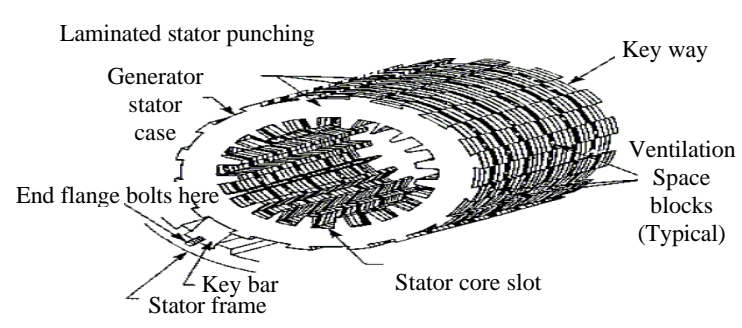

Fig. 1: Generator stator core

To ensure optimal performance of the core without failure, proper design, fabrication techniques, proper material selection and dimensioning is important. The previous data regarding operation history of the core may be one of the useful parameter in this approach. Also, various inspections, measurement and testing of its parameters, etc., may be of great help to ensure proper functioning of the core (Fig. 1).

\section{MATERIALS AND METHODS}

The stator core condition evaluation has been carried out on the basis of attributes and sub-attributes scores. The stator core has been divided into four attributes for scoring purpose named as design and fabrication, history, visual inspection and tests.

Further, these four major attributes have been subdivided into sub-attributes, e.g., the attribute design and fabrication has been subdivided into 6 sub-attributes namely lamination quality, stacking method, radial keys, height, output co-efficient, stator core flanges. Each one of these have been allotted a score point depending upon the various options for a particular sub attributes (Rahi et al., 2007, 2009, 2010).

The 2nd attribute is that of operational history which consists of 5 sub-attributes, e.g., faults in slots, damages by foreign objects, displacement at joints, sliding of laminations and core age.

Similarly, the 5 sub-attributes of the 3 rd attribute visual inspection are dust and dirt, core waviness, sliding of laminations, lamination vibration and 4th and final attribute is based on various measurement and tests for stator core performance. Its sub-attributes are magnetization (Ring) test, bolt tightness, tolerances (like circularity of nominal air gap, verticality and air gap), Elcid test and frame vibration. Each one of sub-attribute has been awarded an arbitrary score based on available options and total of each attribute has been calculated with respect to the maximum score a particular sub- attribute can score (Naidu, 2001; Sharma, 2006) (Table 1).
Table 1: Condition evaluation of generator stator

\begin{tabular}{ll}
\hline Attribute 1 & Design and fabrication \\
\hline Sub-attribute 1A & Lamination quality \\
& After 1980 \\
& $1960-1980$ \\
& $1940-1960$ \\
& $1920-1940$ \\
& Before 1920 \\
Sub-attribute 1B & Stacking method \\
& Continuous \\
& 2-sections \\
& 4 -sections \\
& 6 -sections \\
Sub-attribute 1C & Radial keys \\
& Yes \\
& (External diameter $<7 \mathrm{~m}$ ) \\
& (7>External diameter $<10 \mathrm{~m}$ ) \\
& (External diameter $>10 \mathrm{~m}$ ) \\
Sub-attribute 1D & Height \\
& $<1 \mathrm{~m}$ \\
& $1-2 \mathrm{~m}$ \\
& $>2 \mathrm{~m}$ \\
Sub-attribute 1F & Stator core flanges \\
& $5-10$ fingers \\
& $1-5$ fingers \\
& $>10$ fingers \\
Sub-attribute 1E & Output co-efficient \\
& $<5$ \\
& $5-8$ \\
& $6-7$ \\
& $7-8$ \\
& $8-9$ \\
& \\
&
\end{tabular}

Total attribute 1

Attribute $2 \quad$ Operational history

Sub-attribute 2A Faults in slots

No fault

Phase to ground

Phase to phase

Sub-attribute 2B Damages by for eign objects None

Little

Average

Much

Weightage Evaluation

(n)

6

10

6

0

1

3

5

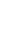

4

5

5

0

1

33

5

1

44

40 (max.) 29

Weightage Evaluation

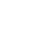

Sub-attribute 2C Displacement at joints

None 0

$<3 \mathrm{~mm}$

$3-5 \mathrm{~mm}$

$5-8 \mathrm{~mm}$

$>8 \mathrm{~mm}$

Sub-attribute 2D Sliding of laminations

None

Little

Average

Much

Sub-attribute $2 \mathrm{E}$ Core age

$<20$ years

20-40 y ears

40-60 y ears

$60-80$ years

$>80$ years

(\#×3) $5 \times 3=15$

$(\# \times 10) \quad 1 \times 10=10$

0

$(\# \times 2)$

(\#×6) $2 \times 6=12$

$(\# \times 10)$

0

3

5
10

10

2

44

4

Total attribute 2

\begin{tabular}{llc}
\hline Attribute 3 & Visual inspection & Weightage Evaluation \\
\hline Sub-attribute 3A & Dust and dirt (\%) & \\
& Ducts blocked $<3$ & 0 \\
& $3-10$ & 1 \\
& $10-30$ & 3 \\
& $30-50$ & 6 \\
Sub-attribute 3B B & $>50$ & 10 \\
& Core waviness & \\
& None & 0 \\
& $<3 \mathrm{~mm}$ & 1 \\
\hline
\end{tabular}


Int. J. Elec. Power Eng., 5 (4): 161-165, 2011

Table 1: Continued

Attribute 3

Visual inspection

(20)

$>8 \mathrm{~mm} \quad 10$

Sub-attribute $3 \mathrm{C}$ Sliding of laminations

None

Little

Average

Much

3

Sub-attribute 3D Lamination vibration (red powder)

None

Little

Average

Much

Sub-attribute 3E Mechanical damage

None

Little

Average

Much

Total attribute 3

Attribute 4

Tests and measurements

Sub-attribute 4A Magnetization (Ring) test

No hot spot

Hot spot $<5$ Deg C

Hot spot 5-10 Deg C

Hot spot $>10$ Deg C

Sub-attribute 4B Bolt tightness

Rated value

$80-100 \%$

$60-80 \%$

$40-60 \%$

$<40 \%$

Sub-attribute 4C Tolerances

4C. A Circularity of nominal

air gap (\%)

$<8$

8-16

16-24

24-32

$32-40$

$>40 \%$

Sub-attribute 4D Verticality (\%)

$<6$

6-12

12-18

$18-24$

24-30

Sub-attribute 4E Air gap (\%)

$<7$

$7-14$

14-21

21-28

28-35

$>35$

Sub-attribute 4F Elcid test

No readings $>50 \mathrm{~mA} \quad 0$

Reading between (50-100) $\mathrm{mA} 4$

Reading between

(100-200) mA

$\geq 2$ reading between

(100-200) $\mathrm{mA}$

$\geq 1>200 \mathrm{~mA}$

Sub-attribute 4G Frame vibration (mm)

$0-0.025$

$0.025-0.075$

$0.075-0.125$

$0.125-0.250$

$>0.250$

Total attribute 4

Maximum score of attributes Gmax $=40+108+40+55=243$

\section{RESULTS AND DISCUSSION}

\section{Formulation:}

- The main attributes taken for stator core condition monitoring are four namely; design and fabrication, history, visual inspection and tests (IEEE Std. 1147 2005, 2006; IEA, 2001; Army corp's of Engineering, 2004)

- Take attributes and sub-attributes for evaluation of stator core condition. Allot weight age to each sub attribute. Calculate total for each sub-attributes. The total number of sub-attribute under attribute design and fabrication (i.e., attribute 1) are six in number

- The score of attribute one is 29 out of maximum score 40

- Similarly, the score of 2 nd attribute is 50 out of maximum score 108 , 3rd attribute score is 23 out of maximum score 40 and the 4 th attribute is 42 out of maximum score of 55

- Now, consider threshold scores for possible conditions based on IEEE guide lines for Hydro electric plant up-gradation

- Then for condition analysis four conditions are being defined, i.e., excellent, good, average and poor condition

Table 2 shows that:

$$
\begin{aligned}
& \text { Total attribute } G_{1}=\sum_{j=1}^{6} \text { sub - attribute } j=40 \\
& \text { Total attribute } G_{2}=\sum_{j=1}^{5} \text { sub - attribute } j=108 \\
& \text { Total attribute } G_{3}=\sum_{j=1}^{5} \text { sub - attribute } j=40 \\
& \text { Total attribute } G_{4}=\sum_{j=1}^{7} \text { sub - attribute } j=55 \\
& \text { Total attribute } G_{5}=\sum_{j=1-4}^{1} G_{j}=243
\end{aligned}
$$

$\mathrm{G}$ is sum of max. scores for all attributes $=243$. The weightage of $\mathrm{G}_{\mathrm{i}}$ defined as $\mathrm{W}_{\mathrm{i}}$ is calculated using Eq. 6 and the data provided in the Table 3. The relative importance of the possible condition $\mathrm{X}_{\mathrm{i}}$ with respect to the attribute $\mathrm{G}_{\mathrm{j}}$ given by weighting $\mathrm{X}_{\mathrm{wij}}$ which is shown in the Table 4 calculated for the threshold for each possible condition.

Now weight age of $\mathrm{G}_{\mathrm{i}}$ is defined by $\mathrm{W}_{\mathrm{i}}$ and is given as ratio of sum of maximum scores for all sub-attributes of attribute $i$ to the sum of maximum score for all attribute. The relative importance or weightage of goals is given by: 
Int. J. Elec. Power Eng., 5 (4): 161-165, 2011

Table 2: Attributes with maximum score

\begin{tabular}{lcc}
\hline Attributes & Max. score & Score achieved \\
\hline Design and fabrication & 40 & 29 \\
Operational history & 108 & 50 \\
Visual inspection & 40 & 23 \\
Tests and measurements & 55 & 42 \\
Total & 243 & - \\
\hline
\end{tabular}

Table 3: Weightage of possible conditions w.r.t. attributes

\begin{tabular}{|c|c|c|c|c|}
\hline $\begin{array}{l}\text { Attributes> } \\
\text { possible } \\
\text { conditions }\end{array}$ & $\begin{array}{l}\text { Design and } \\
\text { fabrication }\end{array}$ & $\begin{array}{c}\text { Operation } \\
\text { history }\end{array}$ & $\begin{array}{c}\text { Visual } \\
\text { inspection }\end{array}$ & $\begin{array}{c}\text { Tests and } \\
\text { mesurements }\end{array}$ \\
\hline Excellent $\left(\mathrm{X}_{1}\right)$ & 0.150 & 0.13889 & 0.125 & 0.18182 \\
\hline $\operatorname{Good}\left(\mathrm{X}_{2}\right)$ & 75 & 0.23148 & 0.250 & 0.38182 \\
\hline Average $\left(\mathrm{X}_{3}\right)$ & 0.375 & 0.32407 & 0.350 & 0.58182 \\
\hline Poor $\left(\mathrm{X}_{4}\right)$ & $>0.375$ & $>0.32407$ & $>0.350$ & $>0.58182$ \\
\hline
\end{tabular}

Table 4: Threshold sc ore for possible conditions

\begin{tabular}{lcccc}
$\begin{array}{l}\text { Attributes }> \\
\begin{array}{l}\text { Possible } \\
\text { conditions }\end{array}\end{array}$ & $\begin{array}{c}\text { Design and } \\
\text { fabrication }\end{array}$ & $\begin{array}{c}\text { Operation } \\
\text { history }\end{array}$ & $\begin{array}{c}\text { Visual } \\
\text { inspection }\end{array}$ & $\begin{array}{c}\text { Tests and } \\
\text { measurements }\end{array}$ \\
Excellent & $<6$ & $<15$ & $<5$ & $<10$ \\
Good & $6-11$ & $15-25$ & $5-10$ & $10-21$ \\
Poor & $11-15$ & $25-35$ & $10-14$ & $21-32$ \\
Worst & $>15$ & $>35$ & $>14$ & $>32$ \\
\hline
\end{tabular}

$$
\mathrm{W}_{\mathrm{i}}=\frac{(\text { S um of } \mathrm{max} \cdot \mathrm{scores} \text { for all sub - attributes } \mathrm{i})}{\sum_{\mathrm{i}=1}^{4} \text { Sum of max.scoresforallsub-attribute }}
$$

Where:

$\mathrm{W}_{1}=$ Weightage of design and fabnrication in analysis

$\mathrm{W}_{2}=$ Weightage of operational history in analysis

$\mathrm{W}_{3}=$ Weightage of visual inspection in analysis

$\mathrm{W}_{4}=$ Weightage of tests and measurements in analysis

$\mathrm{G}_{1}=$ Design and fabrication

$\mathrm{G}_{2}=$ Operational history

$\mathrm{G}_{3}=$ Visual inspection

$\mathrm{G}_{4}=$ Tests and measurements

Let $\mathrm{X}_{\mathrm{i}}$ be the set of possible condition of the generators:

$$
\mathrm{X}=\left\{\mathrm{X}_{\mathrm{i}} / \mathrm{i}=1,2, \ldots \ldots \ldots \ldots \mathrm{n}\right\}
$$

Where:

$\mathrm{X}_{1}=$ The condition of generator is excellent, upgrading could be an option if upgrading of installed capacity is desired otherwise routine maintenance

$\mathrm{X}_{2}=$ The condition of generator is good, upgrading could be an option for modernization as well as uprating capacity and reliability of generation. A constant and careful supervision is required

$\mathrm{X}_{3}=$ The condition of generator is poor, the installed capacity of generation unit is derated, upgrading is the best option for reliable operation of the generator besides that uprating of the installed capacity can be done together at minimum cost
$\mathrm{X}_{4}=$ The condition of generator is worst to bring the generator back to service, upgrading would be the best option together with uprating installed capacity

$\mathrm{G}=\left\{\mathrm{G}_{1}, \mathrm{G}_{2}, \mathrm{G}_{3}, \mathrm{G}_{4}\right\}$ be the set of components or attributes with respect to the present condition of the component or attribute G. The weightage of each alternative is given by set $\mathrm{X}_{\mathrm{w}}$ such that $\mathrm{X}_{\mathrm{w}}=$ $\left\{\mathrm{X}_{\mathrm{w}} / \mathrm{i}=1,2, \ldots 4\right\}$ is given by Eq. 7 :

$$
X_{v i j}=\frac{X_{i} \text { (Thresholdscore) of possiblecondition }}{G_{j} \operatorname{Max}_{j}=1-5}
$$

The value of $\mathrm{X}_{\mathrm{wij}}$ for $\mathrm{i}$ possible conditions $\mathrm{w}_{\mathrm{rt}} \mathrm{j}$ goal or attributes is shown in Table 4 in form of $4 \times 4$ matrix, rows designating possible conditions and column, the attributes of the generator (Table 5). Weightage of possible conditions $\mathrm{w}_{\mathrm{rt}}$ components is calculated by evaluated score of $G_{1}$ divided by max score of $G_{1}$.

$R_{i j}$ is defined as the relative weightage of possible condition $\mathrm{X}_{\mathrm{i}}$ w.r.t. Goal $\mathrm{G}_{\mathrm{j}}$, this is especially important while analyzing each goal individually, $\mathrm{R}_{\mathrm{ij}}$ gives the range for each possible conditions based on the weightage of possible condition w.r.t. weightage of the goal, $\mathrm{R}_{\mathrm{ij}}$ which is given by following Eq. 8:

$$
\mathrm{R}_{\mathrm{ij}}=\mathrm{X}_{\mathrm{ij}} \times \mathrm{W}_{\mathrm{j}}
$$

Where:

$\mathrm{i}=1-4$

$\mathrm{j}=1-5$

Table 4 shows the weightage of possible condition $\mathrm{X}_{\mathrm{i}}$ with respect to the weightage of attributes for the generator condition analysis. Based on these standard ratings and the input data of Table 1, decision making based on condition of five different components of the generator and their weightage. Based on the above rating and weightage given to each attributes as shown below in the set, a threshold for each decision making is fixed. Set $\mathrm{W}$ depicts weightage of each sub-component in the multi-criterion weighted average decision making analysis:

Where:

$$
\mathrm{W}=\left\{\mathrm{W}_{1}, \mathrm{~W}_{2}, \mathrm{~W}_{3}, \mathrm{~W}_{4}\right\}
$$

$\begin{array}{ll}\mathrm{W}_{1}= & 0.16460 \\ \mathrm{~W}_{2}= & 0.44445 \\ \mathrm{~W}_{3}= & 0.16464 \\ \mathrm{~W}_{4}= & 0.22632\end{array}$

Hence, $W=\{0.16460,0.44445,0.16464,0.22632\}$ for the multi-criterion analysis of hydroelectric generator for 
Int. J. Elec. Power Eng., 5 (4): 161-165, 2011

Table 5: Rating of possible conditions w.r.t. attributes

\begin{tabular}{|c|c|c|c|c|c|c|}
\hline Attributes $>$ possible conditions & $X_{\mathrm{wgij}}$ & Design and fabrication & Operation history & Visual inspection & Tests and measurements & Range of possible conditions \\
\hline Excellent $\left(\mathrm{X}_{1}\right)$ & $\mathrm{X}_{1}$ & 0.02469 & 0.06173 & 0.02058 & 0.04115 & 0.14815 \\
\hline Good $\left(\mathrm{X}_{2}\right)$ & $\mathrm{X}_{2}$ & 0.04527 & 0.10288 & 0.04115 & 0.08642 & 0.25572 \\
\hline Verage $\left(X_{3}\right)$ & $\mathrm{X}_{3}$ & 0.06173 & 0.14403 & 0.05761 & 0.13169 & 0.39506 \\
\hline Poor $\left(\mathrm{X}_{4}\right)$ & $\mathrm{x}_{4}$ & $>0.06173$ & $>0.14403$ & $>0.05761$ & $>0.13169$ & 0.39506 \\
\hline
\end{tabular}

Table 6: Possible conditions and their range

\begin{tabular}{ll}
\hline Decision/possible condition $\left(\mathrm{X}_{\mathrm{i}}\right)$ & Range of values \\
\hline Excellent $\left(\mathrm{X}_{1}\right)$ & $0-0.14815$ \\
Good $\left(\mathrm{X}_{2}\right)$ & $0.14815-0.27572$ \\
Poor $\left(\mathrm{X}_{3}\right)$ & $0.27572-0.39506$ \\
Very poor/worst $\left(\mathrm{X}_{4}\right)$ & $>0.39506$ \\
\hline
\end{tabular}

upgrading study. In Table 5, the range for the decision criterion is calculated, based on relative weightings of attribute with respect to the possible conditions. The range for formulating the decision criterion based on Table 6 is given by Eq. 9:

$$
\text { Range for } X_{i}=\sum_{j=1}^{5} R_{i j}
$$

Table 3 and 4 show the decision and the corresponding range of values for decision making guidelines.

\section{CONCLUSION}

Depending upon the score earned by the various equipments/components of generators and based upon the threshold score the four conditions of each components viz., excellent condition, good condition, poor condition and worst condition have been identified. Also, the relative weight age for each condition has been calculated so as to minimize the effect of over influence by the individual sub-attribute. Finally, the range of values has been calculated for the said four possible conditions for the generator as a whole. This study therefore, presents a new empirical technique for the evaluation of the condition of the stator core of a hydro generators whereby utility can decide about the various approaches for the refurbishment, up rating or rehabilitation of the stator.

\section{REFERENCES}

IEEE Std. 1147-2005, 2006. IEEE guide for the rehabilitation of hydroelectric power plants. March 22, 2006, Pages: 51. http://ieeexplore.ieee.org/xpl/mostRecentIssue. jsp?punumber $=10722$.

Naidu, B., 2001. Diagnostic Testing of Hydro Generators. CBS Publishers and Distributers, New Delhi, pp: 261-276.

Rahi, O.P. and N. Kumar, 2007. Reliability criteria for aged hydro power plants. Proceedings of the National Conference on Quality, Reliability and Maintainability Aspects in Engineering Systems, December 27-28, 2007, NIT Hamirpur (HP), India, pp: 103-107.

Rahi, O.P., A.K. Chandel and M.G. Sharma, 2009. Refurbishment of aged hydro power plant-a case study. Proceedings of the International Conference, Small Hydro, April, 28-29, The Renaissance Vancouver Hotel, Vancouver (Canada) Organized By International Water Power and Dam Construction (Canada).

Rahi, O.P., A.K. Chandel and M.G. Sharma, 2010. Refurbishment and uprating of old hydro power plants. Indian J. Power River Valley Dev., 60: 143-147.

Sharma, S.R., 2006. Feasibility study of options for aging hydro-power generation facility. Chap. 3, pp: 25-53. http://dspace.uta.edu/handle/10106/252. 